\title{
Early diagnosis is critical to ensure good outcomes in HIV-infected children: Outlining barriers to care
}

\author{
Feucht UD ${ }^{1}$, Meyer $\mathrm{A}^{1}$, Thomas $\mathrm{WN}^{1}$, Forsyth BWC ${ }^{1,2}$, Kruger $\mathrm{M}^{3}$ \\ Department of Paediatrics, Kalafong Hospital, University of Pretoria, South Africa \\ Department of Pediatrics, Yale University, New Haven, CT, United States of America \\ Department of Paediatrics and Child Health, University of Stellenbosch, South Africa
}

Post-print version. Full reference: Feucht UD, Meyer A, Thomas WN, Forsyth BWC, Kruger M. Early diagnosis is critical to ensure good outcomes in HIV-infected children - Outlining barriers to care. Published: AIDS Care. 2015. doi: 10.1080/09540121.2015.1066748

\begin{abstract}
HIV-infected children require early initiation of antiretroviral therapy (ART) to ensure good outcomes. The aim was to investigate missed opportunities in childhood HIV diagnosis leading to delayed ART initiation.

Baseline data was reviewed of all children aged $<15$ years referred over a one-year period for ART initiation to the Kalafong Hospital HIV services in Gauteng, South Africa. Of the 250 children, one quarter $(24.5 \%)$ were of school-going age, $34.5 \%$ in the preschool group, $18 \%$ between 6-12 months old and 23\% below six months of age (median age $=1.5$ years [IQR 0.5 4.8]). Most children (82\%) presented with advanced/severe HIV disease, particularly those aged 6-12 months (95\%). Malnutrition was prominent and referrals were mostly from hospital inpatient services $(61 \%)$.

A structured caregiver interview was conducted in a subgroup, with detailed review of medical records and HIV results. The majority $(\geq 89 \%)$ of the 65 interviewed caregivers reported good access to routine healthcare, except for postnatal care (26\%). Maternal HIV-testing was mostly done during the $2^{\text {nd }} \& 3^{\text {rd }}$ pregnancy trimesters $(69 \%)$. Maternal non-disclosure of HIV status was common $(63 \%)$ and $83 \%$ of mothers reported a lack of psychosocial support. Routine infant HIV-testing was not done in $66 \%$, and inadequate reporting on patient-held records (Road-toHealth Cards/Booklets) occurred frequently $(74 \%)$. Children with symptomatic HIV disease were not investigated at primary healthcare in $53 \%$, and in $68 \%$ of families the siblings were not tested. One-third of children (35\%) had a previous HIV diagnosis, with $77 \%$ of caregivers aware of these prior results, while $50 \%$ acknowledged failing to attend ART-services despite referral.

In conclusion, a clear strategy on paediatric HIV case finding, especially at primary healthcare, is vital. Multiple barriers need to be overcome in the HIV care pathway to reach high uptake of services, of which especially maternal reasons for not attending paediatric ART services need further exploration.
\end{abstract}




\section{Introduction}

Childhood HIV infection, linked secondarily to the adult pandemic, profoundly impacts on paediatric morbidity and mortality in high-burden countries (Stephen, Bamford, Patrick, \& Wittenberg, 2011). The Prevention-of-Mother-to-Child Transmission (PMTCT) programme, implemented in South Africa from 2002 and evolving since, mitigates this detrimental impact through reduction of HIV transmission to children using sequential interventions during pregnancy, at and after birth, up until childhood HIV diagnosis (Barron et al., 2013; Department of Health (DOH), 2008; DOH, 2013). Advances in antiretroviral therapy (ART) now enable good outcomes for HIV-infected children if therapy is initiated early (Violari et al., 2008). The South African ART programme commenced in 2004, cumulatively enrolling large numbers of adults on treatment, whereas paediatric ART access has lagged behind, similar to other SubSaharan countries (Ahmed et al., 2013; DOH, 2004; Johnson, 2012).

Diagnostic strategies should identify and test at-risk children and establish linkages to care (Ahmed et al., 2013). Extensive focus on testing HIV-exposed children from the PMTCT programme has resulted in steadily increasing HIV DNA PCR testing numbers, with majority of tests yielding negative results (Barron et al., 2013). Identification of children missed by PMTCT testing has received less attention, like those with early symptomatic disease potentially identified at primary healthcare through the Integrated Management of Childhood Illnesses (IMCI) programme (DOH, 2011). Targeted testing of children of HIV-infected adults, sibling testing of known HIV-infected children and systematic testing within malnutrition and tuberculosis (TB) programmes furthermore requires high priority (Ahmed et al., 2013; Kellerman \& Essajee, 2010). Meticulous documentation on patient-held records, like the South African Road-to-Health Card/Booklet (RTHC/RTHB), can further contribute towards earlier identification and testing of at-risk children (Horwood, Voce, Vermaak, Rollins \& Qazi, 2010).

Kalafong Hospital, an early South African public sector ART site, rapidly evolved into a large adult and paediatric treatment centre, initiating close to 900 children on ART prior to study commencement. It had never experienced a significant waiting list for new paediatric referrals and had close links with the inpatient services, ensuring rapid referral and ART initiation, ideally before hospital discharge. Referrals were additionally received from primary healthcare facilities, which at time of study were not initiating paediatric ART in substantial numbers (Massyn et al., 2013). The study aim was to describe the characteristics of children at time of ART referral, with detailed description of the path leading to childhood HIV diagnosis and emphasis on barriers to care.

\section{Methods}

We reviewed baseline data of all HIV-infected children $<15$ years of age newly seen at the Kalafong Paediatric HIV services between June 2009 and May 2010. Data collection included demographic data, disease severity (nutritional status; World Health Organization staging (WHO, 2007)), laboratory data (CD4 counts/percentages; HIV viral loads) and three-year follow-up (deaths; loss-to-care).

For descriptive purposes the cohort was subdivided according to age: The first year of life, when early infant diagnosis and rapid HIV disease progression occur, was further split into the first and 
second six months (' 0 to $<6 \mathrm{~m}$ '; ' 6 to $<12 \mathrm{~m}$ '), pre-schoolers were allocated to the ' 1 to $<3 \mathrm{y}$ ' or ' 3 to $<5$ y' groups and schoolchildren were assigned to the ' 5 to $<15 y$ ' group.

A structured caregiver interview obtained a detailed social and clinical history regarding the mother-child pathway through PMTCT until childhood HIV diagnosis and ART referral. This subgroup included a convenience sample of 65 caregivers of children born during the South African PMTCT era: Study participants born before February 2008 were from the single-dose nevirapine (sdNVP) period (DOH, 2000), with those born thereafter from the dual-therapy era (added antenatal/postnatal zidovudine) (DOH, 2008). We furthermore studied the child's medical records (clinical notes; patient-held RTHC/RTHB), maternal medical records (if available) and National Health Laboratory Service database (HIV results).

The Ethics Review Committee, Faculty of Health Sciences, University of Pretoria, approved the study protocol.

\section{Results}

The 250 newly-diagnosed HIV-infected children had a male-to-female ratio of 1.02:1, with also no female predominance in the ' 10 to $15 y$ ' group ( 12 boys; 9 girls). The median age was 1.5 years [interquartile range 0.5-4.8], with one-quarter being schoolchildren $(\mathrm{n}=61 ; 24.5 \%)$ and $86(34.5 \%)$ pre-schoolers (Table 1). Another 45 children $(18 \%)$ were identified during the second six months of life and 58 children (23\%) within the first six months, including 16 children younger than three months (four were asymptomatic/WHO Stage 1). The majority of children (82\%) had advanced or severe disease (WHO Stages 3/4) (Figure 1) and referrals were mainly (61\%) from hospital inpatient services, while $21 \%$ were sent from primary healthcare facilities and $17 \%$ from the hospital's outpatient services.

Malnutrition was prominent. The mean weight-for-age Z-score was -2.3 (standard deviation (SD) 1.8 ), with $53 \%$ being underweight (Z-score $<-2)$ and $28 \%$ severely underweight $(Z$-score $<-3)$ (WHO, 2006). Short stature was equally prevalent, with a mean height-for-age Z-score of -2.0 (SD 1.6) and 46\% stunted (Z-score $<-2$ ) and 23\% severely stunted (Z-score $<-3$ ). Wasting (Zscore $<-2)$ occurred in 38\% and severe wasting (Z-score $<-3)$ in one-fifth $(21 \%)$, with a mean body mass index (BMI)-for-age of -1.6 (SD 2.0). Infants in the ' 6 to $<12 \mathrm{~m}$ ' group were most severely affected: $76 \%$ were underweight, $57 \%$ stunted and wasted and $95 \%$ had advanced/severe HIV disease. One-fifth of children had microcephaly (head circumference $(\mathrm{HC})<-2 \mathrm{SD})$ ('0 to $<12 \mathrm{~m}$ ' $=22 \%$; ' 1 to $<5 \mathrm{y}$ ' $=20 \%$ ), while percentages for severe microcephaly $(\mathrm{HC}<-3 \mathrm{SD})$ were $14 \%$ and $6 \%$ respectively in the age groups. The mean HC-for-age Z-score was -1.0 (SD 1.5) (HC measured in $<5 \mathrm{y}$ ).

The mean CD4\% was 16.9\% (SD 9.5) and absolute CD4 count 822 cells/ $\mu$ l (SD 742). Regarding CD4 categories (WHO, 2007), two-thirds (66\%) had advanced/severe immunosuppression on presentation; most severe in ' 6 to $<12 \mathrm{~m}$ ' group ( $80 \%$ ). HIV viral loads (VL) were high throughout, with a mean $\operatorname{VLlog}_{10}=5.0$ (SD 1.2). 
Table 1: Clinical and laboratory characteristics of the cohort according to age groups

\begin{tabular}{|c|c|c|c|c|c|c|c|c|}
\hline & & & & & & & & \multirow{3}{*}{$\begin{array}{l}\text { Total } \\
(n=250)\end{array}$} \\
\hline & & & \multicolumn{2}{|c|}{$\begin{array}{l}<\mathbf{1 2 m} \\
(\mathrm{n}=103)\end{array}$} & \multicolumn{2}{|c|}{$\begin{array}{c}1 \text { to }<5 \mathbf{y} \\
(\mathrm{n}=86)\end{array}$} & \multirow[t]{2}{*}{$\begin{array}{c}5 \text { to }<15 y \\
(n=61)\end{array}$} & \\
\hline & & & $\begin{array}{c}\mathbf{0} \text { to }<6 \mathbf{6 m} \\
(\mathrm{n}=58)\end{array}$ & $\begin{array}{c}\mathbf{6} \text { to }<\mathbf{1 2 m} \\
(\mathrm{n}=45)\end{array}$ & $\begin{array}{c}1 \text { to }<3 y \\
(n=62)\end{array}$ & $\begin{array}{c}3 \text { to }<5 y \\
(n=24)\end{array}$ & & \\
\hline \multirow{4}{*}{$\begin{array}{l}\text { Nutritional } \\
\text { Parameters* }\end{array}$} & Weight-for-age Z-score & \multirow{6}{*}{$\begin{array}{l}\text { Mean (SD) } \\
\text { (Missing) }\end{array}$} & $-2.4(2.0)(0)$ & $-3.1(1.5)(0)$ & $-2.2(1.7)(0)$ & $-1.9(1.5)(0)$ & $-1.8(1.8)(21)$ & $-2.3(1.8)(21)$ \\
\hline & Height-for-age Z-score & & $-1.9(2.1)(3)$ & $-2.3(1.7)(1)$ & $-2.1(1.5)(1)$ & $-2.3(1.2)(1)$ & $-1.8(1.4)(1)$ & $-2.0(1.6)(7)$ \\
\hline & BMI-for-age Z-score & & $-1.8(1.9)(3)$ & $-2.4(1.9)(1)$ & $-1.3(1.8)(1)$ & $-0.6(2.0)(1)$ & $-1.4(2.2)(1)$ & $-1.6(2.0)(7)$ \\
\hline & HC-for-age Z-score & & $-0.9(1.8)(2)$ & $-1.2(1.4)(2)$ & $-0.9(1.4)(4)$ & $-0.8(1.3)(11)$ & N/A & $-1.0(1.5)(80)$ \\
\hline \multirow[t]{2}{*}{ CD4 } & CD4 absolute count & & 1345 (994) (4) & $899(825)(1)$ & $780(500)(1)$ & $755(484)(0)$ & $373(266)(0)$ & $822(742)(6)$ \\
\hline & $\mathrm{CD} 4 \%$ & & $19.8 \%(10.3)(4)$ & $15.9 \%(8.9)(1)$ & $16.7 \%(9.5)(1)$ & $18.8 \%(8.2)(0)$ & $14.3 \%(9.0)(0)$ & $16.9 \%(9.5)(6)$ \\
\hline HIV viral load & Viral load $\log _{10}$ & & $5.6(1.2)(9)$ & $5.5(1.1)(6)$ & $5.1(1.1)(7)$ & $4.5(1.2)(0)$ & $4.4(0.9)(4)$ & $5.0(1.2)(26)$ \\
\hline \multirow[t]{4}{*}{ Referral site } & Primary healthcare facility & \multirow{6}{*}{ Percentage } & $27.5 \%$ & $13 \%$ & $21 \%$ & $21 \%$ & $20 \%$ & $21 \%$ \\
\hline & Hospital outpatients & & $8.5 \%$ & $9 \%$ & $21 \%$ & $25 \%$ & $23 \%$ & $17 \%$ \\
\hline & Hospital inpatients & & $62 \%$ & $76 \%$ & $58 \%$ & $54 \%$ & $54 \%$ & $61 \%$ \\
\hline & Other** & & $2 \%$ & $2 \%$ & $0 \%$ & $0 \%$ & $3 \%$ & $2 \%$ \\
\hline \multirow[t]{2}{*}{ Death } & Within $6 \mathrm{~m}$ of referral & & $16 \%$ & $18 \%$ & $8 \%$ & $0 \%$ & $0 \%$ & $9 \%$ \\
\hline & From 6 to $36 \mathrm{~m}$ of referral & & $2 \%$ & $4 \%$ & $4 \%$ & $0 \%$ & $3 \%$ & $3 \%$ \\
\hline \multirow[t]{2}{*}{ Loss-to-care } & Within $6 \mathrm{~m}$ of referral & & $22 \%$ & $13 \%$ & $19 \%$ & $8 \%$ & $11 \%$ & $16 \%$ \\
\hline & From 6 to $36 \mathrm{~m}$ of referral & & $5 \%$ & $16 \%$ & $9 \%$ & $17 \%$ & $2 \%$ & $9 \%$ \\
\hline
\end{tabular}

Abbreviations: $\mathrm{m}=$ months; $\mathrm{y}=$ years; $\mathrm{BMI}=$ body mass index; $\mathrm{HC}=$ head circumference, $\mathrm{SD}=$ standard deviation; $\mathrm{N} / \mathrm{A}=$ not applicable

*Age- and sex-adjusted nutritional parameters in Z-scores, using WHO reference standards (WHO, 2006)

**Other referral sites include private sector and other hospitals 
Figure 1: Severity of childhood HIV disease, malnutrition and immunological suppression at presentation for care, according to age groups $(n=250)$

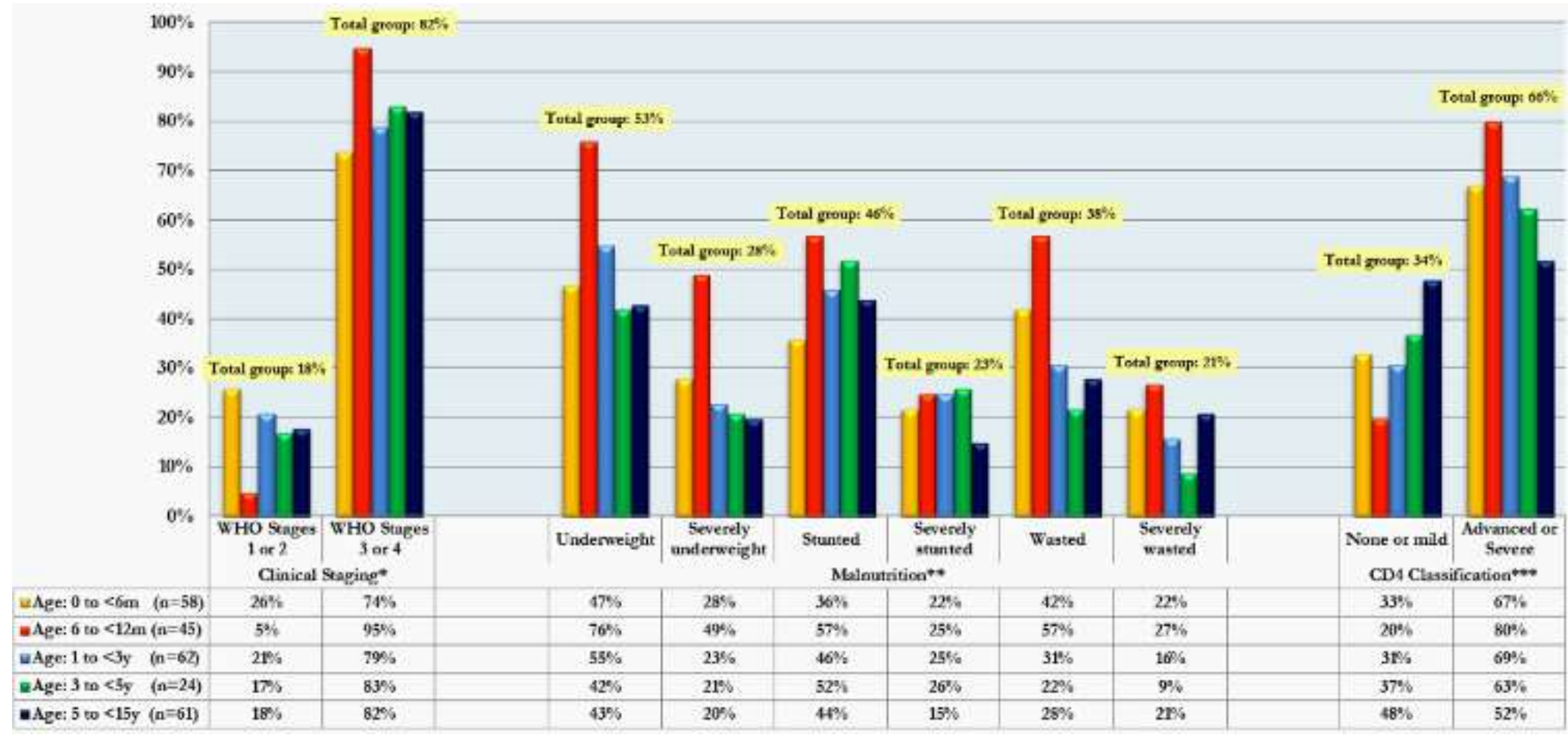

Legend for figure 1:

Abbreviations: $\mathrm{WHO}=$ World Health Organization; $\mathrm{m}=$ months; $\mathrm{y}=$ years

*Clinical staging for HIV in Children and Adolescents (WHO, 2007) (One case each not documented in age groups ' 0 to $<6 \mathrm{~m}$ ' and ' 6 to $<12 \mathrm{~m}$ ')

**Nutritional classification indicating percentage of cohort with malnutrition (WHO, 2006)

- Underweight: Weight-for-age (W/A) Z-score <-2SD; Severely underweight: W/A Z-score <-3SD

- Stunted: Height-for-age (H/A) Z-score <-2SD; Severely stunted: H/A Z-score <-3SD

- Wasted: Body mass index (BMI) Z-score <-2SD; Severely wasted: BMI Z-score <-3SD

***CD4 classification (WHO, 2007):

- None: $>35 \%($ age $<12 \mathrm{~m}) ;>25 \%($ age $13-59 \mathrm{~m}) ;>500 / \mathrm{mm}^{3}($ age $>5 \mathrm{y})$

- Mild: $25-34 \%($ age $<12 \mathrm{~m}) ; 20-24 \%$ (age $13-59 \mathrm{~m}) ; 350-499 \mathrm{~mm}^{3}$ (age $\left.>5 \mathrm{y}\right)$

- $\quad$ Advanced: $20-24 \%($ age $<12 \mathrm{~m}) ; 15-19 \%($ age $13-59 \mathrm{~m}) ; 200-349 \mathrm{~mm}^{3}($ age $>5 \mathrm{y})$

- Severe: $<20 \%($ age $<12 \mathrm{~m}) ;<15 \%($ age $13-59 \mathrm{~m}) ;<200 \mathrm{~mm}^{3}($ age $>5 \mathrm{y})$ 
The late presentation resulted in 22 deaths ( $9 \%$ ) within six months of ART (21 from inpatient referrals), with the highest mortality $(18 \%)$ in the ' 6 to $<12 \mathrm{~m}$ ' group. Another 40 children (16\%) were lost-to-care within six months (33 were inpatient referrals), with additional $9 \%$ loss-to-care later. Therefore over one-third of children (37\%) were lost, either to death or follow-up, within three years of ART referral.

\section{The pathway to childhood ART access:}

The 65 in-depth interviews revealed that majority of families lived under poor socio-economic circumstances (Table 2): Only 45\% had regular employment, 58\% lived in brick houses, less than half $(42 \%)$ had running water inside the home and $97 \%$ used public transportation. At time of interview nine children (14\%) were not in maternal care, including four maternal orphans $(6 \%)$. Mothers were slightly younger at time of birth than fathers (maternal mean age $=28.5 \mathrm{y}$ (SD 6.2), paternal mean age $=34 \mathrm{y}$ (SD 11.3)). At time of interview six fathers had died, while eight were unwell and the whereabouts of four fathers was unknown. Twenty fathers $(32 \%)$ were known HIV-infected, the remaining had not tested or caregivers were unaware of the results. Forty study participants had siblings, but in 27 of these families $(68 \%)$ sibling testing had not been done.

Mothers had excellent access to antenatal care (97\%), and 63\% had attended at least four antenatal visits. Maternal HIV-testing was mostly done during the second $(32 \%)$ or third $(37 \%)$ trimesters, while 13 mothers $(20 \%)$ had no antenatal HIV test and two women (4\%) had not received their results (Table 3). Post-test counselling had not been provided to $13 \%$ of those tested and $83 \%$ of women reported lack of psychosocial support. Of the 49 mothers who tested for HIV before/during pregnancy, 63\% had not disclosed their HIV status to anyone during pregnancy. Antenatal infant feeding counselling was not done in one-third (34\%), while $72 \%$ were not screened for TB during pregnancy.

Majority of births (97\%) occurred within healthcare facilities, but in one-third of cases $(33 \%)$ health workers attending to the delivery were unaware of the maternal HIV infection. In two-thirds of motherinfant-pairs appropriate ART interventions were not administered and inadequate infant feeding counselling occurred in one-quarter (23\%). Early postnatal care occurred in only $26 \%$, but most infants $(89 \%)$ attended healthcare at age six weeks, with $29 \%$ of mothers utilizing a different health facility compared to antenatal care. The PMTCT coding, previously used to implicitly indicate HIV exposure, was charted incorrectly on $61 \%$ of RTHCs ( $n=46$ ), while on $74 \%$ there was lack of documentation of HIV PCR results, infant feeding choice and cotrimoxazole prophylaxis.

One infant had a positive HIV DNA PCR at birth and 20 infants (31\%) were tested at six weeks (as per PMTCT guidelines). Three mothers reported an initial negative HIV result, but one case was found to have been positive on laboratory review. Maternal barriers to childhood ART access included not returning for the child's HIV or CD4 results ( $\mathrm{n}=1 \mathrm{each}$ ) because of maternal anxiety and shame. Not attending ART care after referral was due to maternal fear $(n=2)$, traditional health practitioner visit $(\mathrm{n}=1)$ and undisclosed reason $(\mathrm{n}=1)$. Health system barriers included repeat PCR due to specimen loss $(\mathrm{n}=1)$, inability to retrieve the child's HIV or CD4 results $(\mathrm{n}=1$ each) and delay in appointment $(\mathrm{n}=1)$. In some infants no CD4 count, clinical staging or ART-initiation/referral was done ( $\mathrm{n}=4$ respectively) despite a positive PCR test, including two cases in whom incorrect information was provided regarding ART eligibility. 
Table 2: Socio-demographic characteristics and information on HIV-testing (interview subgroup; $\mathrm{n}=65$ )

\begin{tabular}{|c|c|c|c|}
\hline \multirow{7}{*}{$\begin{array}{l}\text { Socio- } \\
\text { demographic } \\
\text { characteristics }\end{array}$} & Parental age at child's birth & $\begin{array}{l}\text { Maternal age (Mean (SD) (range)) } \\
\text { Paternal age (Mean (SD) (range)) }\end{array}$ & $\begin{array}{l}28.5 y(6.2)(17-42) \\
34 y(11.3)(26-42)\end{array}$ \\
\hline & Household members & Number (Mean (SD) (range)) & $4.7(2.3)(2-14)$ \\
\hline & Caregiver & $\begin{array}{l}\text { Mother is primary caregiver } \\
\text { Different caregivers over time }\end{array}$ & $\begin{array}{l}86 \% \\
14 \%\end{array}$ \\
\hline & Child's rank in household & $\begin{array}{l}1^{\text {st }} \text { child } \\
2^{\text {nd }} \text { child } \\
3^{\text {rd }} \text { child or more }\end{array}$ & $\begin{array}{l}38 \% \\
42 \% \\
20 \%\end{array}$ \\
\hline & Housing & $\begin{array}{l}\text { Permanent brick structure } \\
\text { Running water indoors }\end{array}$ & $\begin{array}{l}58 \% \\
42 \%\end{array}$ \\
\hline & Main source of income & $\begin{array}{l}\text { Regular income employment } \\
\text { Temporary employment } \\
\text { Grants } \\
\text { Grandparent's state pension }\end{array}$ & $\begin{array}{l}45 \% \\
15 \% \\
23 \% \\
17 \%\end{array}$ \\
\hline & Transport to health facility & $\begin{array}{l}\text { Communal taxi } \\
\text { Public transport (bus or train) } \\
\text { Private transport }\end{array}$ & $\begin{array}{l}94 \% \\
3 \% \\
3 \%\end{array}$ \\
\hline \multirow[t]{2}{*}{$\begin{array}{l}\text { Parental HIV- } \\
\text { testing }\end{array}$} & Maternal HIV-testing & $\begin{array}{l}\text { Pre-conceptual } \\
1^{\text {st }} \text { trimester of pregnancy } \\
2^{\text {nd }} \text { trimester of pregnancy } \\
3^{\text {rd }} \text { trimester of pregnancy } \\
\text { After delivery }\end{array}$ & $\begin{array}{c}2 \% \\
9 \% \\
32 \% \\
37 \% \\
20 \%\end{array}$ \\
\hline & Paternal HIV status & $\begin{array}{l}\text { Positive } \\
\text { Negative } \\
\text { Never tested/ refused/ unknown }\end{array}$ & $\begin{array}{l}32 \% \\
0 \% \\
68 \%\end{array}$ \\
\hline \multirow{3}{*}{$\begin{array}{l}\text { Child's HIV- } \\
\text { testing and } \\
\text { referral }\end{array}$} & $\begin{array}{l}\text { Reason for HIV test, which } \\
\text { led to referral }\end{array}$ & $\begin{array}{l}\text { Birth/ 6w PCR* } \\
\text { HIV exposure identified } * * \\
\text { Symptomatic } * * *\end{array}$ & $\begin{array}{c}14 \% \\
8 \% \\
78 \%\end{array}$ \\
\hline & ART access interval & $\begin{array}{l}\text { From HIV test to ART attendance } \\
\text { (Median [IQR]) }\end{array}$ & $18 \mathrm{~d}[41]$ \\
\hline & Age at $1^{\text {st }}$ ART clinic visit & Age in years (Mean (SD) (range)) & $1.4 \mathrm{y}(1.7)(0.1-8.2)$ \\
\hline
\end{tabular}

Abbreviations: $\mathrm{SD}=$ standard deviation; $\mathrm{y}=$ years; $\mathrm{w}=$ weeks; $\mathrm{PCR}=$ polymerase chain reaction; $\mathrm{ART}=$ antiretroviral therapy; $\mathrm{IQR}=$ interquartile range; $\mathrm{d}=$ days; $\mathrm{m}=$ months; $\mathrm{WHO}=$ World Health Organization

*PCR done at birth in one case

** Timing of test: Post-weaning=2; At 18m=1; Retest after loss-to-care=1; Presenting with minor illness=1

***Symptomatic HIV disease: WHO Stage 2 in 2 cases, WHO Stage 3 in 12 cases; WHO Stage 4 in 37 cases 
Table 3: Barriers to access to paediatric HIV care (interview subgroup, $n=65$ )

\begin{tabular}{|c|c|c|c|c|}
\hline Antenatal care & $\begin{array}{l}\text { No antenatal care } \\
\text { No maternal HIV test in pregnancy } \\
\text { Mother did not receive HIV result } \\
\text { No post-test counselling } \\
\text { No HIV disclosure during pregnancy } \\
\text { No infant feeding counselling } \\
\text { No psychosocial support offered } \\
\text { No TB screening in pregnancy }\end{array}$ & $\begin{array}{l}n=52 \\
n=65\end{array}$ & $\begin{array}{l}3 \% \\
20 \% \\
4 \% \\
13 \% \\
63 \% \\
34 \% \\
83 \% \\
72 \%\end{array}$ & $\begin{array}{l}\text { No HIV test }=13 \\
\text { Unknown }=1\end{array}$ \\
\hline $\begin{array}{l}\text { Labour } \\
\text { delivery }\end{array}$ & $\begin{array}{l}\text { Delivery did not take place at health } \\
\text { facility } \\
\text { Maternal HIV infection not known at } \\
\text { delivery } \\
\text { Maternal ART not given as per guideline } \\
\text { Infant ART not given as per guideline } \\
\text { No infant feeding counselling }\end{array}$ & $\mathrm{n}=63$ & $\begin{array}{l}33 \% \\
65 \% \\
66 \% \\
23 \% \\
\end{array}$ & Home birth=1; unknown=1 \\
\hline $\begin{array}{l}\text { Postnatal access to } \\
\text { care }\end{array}$ & $\begin{array}{l}\text { Different postnatal than antenatal clinic } \\
\text { No early postnatal care } \\
\text { No healthcare visit at } 6 \mathrm{w} \\
\text { No HIV PCR at } 6 \mathrm{w} \\
\text { No cotrimoxazole prophylaxis given at } 6 \mathrm{w} \\
\text { No follow-up scheduled for PCR result } \\
\text { Mother did not return for PCR result } \\
\text { No clinical staging after PCR result } \\
\text { No CD4 count after PCR result } \\
\text { No ART-referral for child } \\
\text { Weaning advised after positive PCR }\end{array}$ & $\mathrm{n}=21$ & $\begin{array}{l}29 \% \\
74 \% \\
11 \% \\
66 \% \\
69 \% \\
0 \% \\
5 \% \\
24 \% \\
24 \% \\
24 \% \\
45 \% \\
\end{array}$ & $\begin{array}{l}\text { No 6w PCR }=43 \\
\text { Initial PCR negative }=2 \\
\text { Unknown }=1 \\
\text { No } \quad \text { CD } 4 \quad \text { result }=1 \text {; } \\
\text { unknown }=1 \\
\text { Unknown }=1 \\
\text { Formula feeding }=7\end{array}$ \\
\hline $\begin{array}{l}\text { Use of patient-held } \\
\text { Road-to-Health } \\
\text { Card }\end{array}$ & $\begin{array}{l}\text { Incorrect charting of implicit PMTCT } \\
\text { code } \\
\text { No documentation that HIV PCR was } \\
\text { done } \\
\text { No documentation of HIV PCR result } \\
\text { Infant feeding choice not charted } \\
\text { Cotrimoxazole prophylaxis not charted }\end{array}$ & $n=46$ & $\begin{array}{l}70 \% \\
74 \% \\
74 \% \\
74 \%\end{array}$ & RTHC unavailable $=19$ \\
\hline $\begin{array}{l}\text { IMCI clinical criteri } \\
\text { for HIV-testing* }\end{array}$ & $\begin{array}{l}\text { Symptomatic children with documented } \\
\text { IMCI criteria on RTHC with no HIV- } \\
\text { testing done }\end{array}$ & $\mathrm{n}=17$ & $53 \%$ & $\begin{array}{l}1 \quad \text { or } \quad 2 \quad \text { criteria }=6 ; \\
\geq 3 \text { criteria }=11\end{array}$ \\
\hline $\begin{array}{l}\text { HIV disease / } \\
\text { comorbidities at } \\
\text { ART presentation }\end{array}$ & $\begin{array}{l}\text { Advanced/ severe HIV disease } \\
\text { Moderate/ severe malnutrition } \\
\text { TB diagnosis prior to/ at ART referral } \\
\text { HIV-testing not done at TB diagnosis } \\
\text { No cotrimoxazole prophylaxis at ART } \\
\text { referral }\end{array}$ & $\begin{array}{l}n=65 \\
n=23 \\
n=65\end{array}$ & $\begin{array}{c}82 \% \\
63 \% \\
35 \% \\
9 \% \\
68 \%\end{array}$ & \\
\hline $\begin{array}{l}\text { Prior HIV-testing } \\
\text { of child }\end{array}$ & $\begin{array}{l}\text { Positive HIV test prior to current diagnosis } \\
\text { Caregiver aware of previous HIV result } \\
\text { Previous HIV result on laboratory } \\
\text { database } \\
\text { Previous ART referral but non-attendance } \\
\text { Previous ART attendance, but loss-to-care }\end{array}$ & $\mathrm{n}=65$ & $\begin{array}{l}35 \% \\
77 \% \\
43 \%\end{array}$ & $\begin{array}{l}\text { Unknown=1 } \\
\text { Unknown=1 }\end{array}$ \\
\hline
\end{tabular}

Abbreviations: $\mathrm{TB}=$ tuberculosis; $\mathrm{ART}=$ antiretroviral therapy; $\mathrm{w}=$ weeks $; \mathrm{PCR}=$ polymerase chain reaction; $\mathrm{IMCI}=$ Integrated Management of Childhood Illnesses; RTHC= Road-to-Health Card

*IMCI: Clinical criteria for HIV-testing (DOH, 2011):

- Criteria: Pneumonia, persistent diarrhoea, ear discharge, low weight-for-age, unsatisfactory weight gain, ora thrush, parotid enlargement and enlarged lymph glands in the neck, axilla or groin

- No criteria $=$ HIV infection unlikely; 1 or 2 criteria $=$ possible HIV infection; $\geq 3$ criteria $=$ suspected symptomatic HIV infection 
Early infant diagnosis, if done, therefore did not guarantee access to appropriate HIV care. Only nine infants $(14 \%)$ presented for ART due to routine early infant PCR testing, of whom four were already symptomatic (WHO Stages 3/4). Another five asymptomatic children (ages 3-18 months) were identified as HIV-exposed and tested, including post-weaning testing $(\mathrm{n}=2), 18$ month-testing $(n=1)$, retesting after loss-to-care $(n=1)$ and testing at minor illness $(n=1)$. In the remaining 51 children (78\%), HIV-testing was done because of symptomatic disease.

The IMCI criteria, aimed at alerting health workers at primary healthcare facilities to consider early symptomatic HIV disease (DOH, 2011), were documented on RTHCs but with no HIVtesting done in $53 \%$ of the symptomatic children. Majority $(82 \%)$ of children had advanced/severe disease at presentation. Besides the prevalent malnutrition, 23 children $(35 \%)$ had previous/current TB, with HIV-testing at TB diagnosis not done in two cases (9\%). Other WHO Stage 3 conditions were oral candidiasis (25\%) and chronic diarrhoea (15\%), while WHO Stage 4 events included Pneumocystis jiroveci pneumonia (11\%), HIV encephalopathy $(6 \%)$ and recurrent severe bacterial infections $(6 \%)$.

Past medical history revealed that 23 children (35\%) had prior HIV-testing done, with 18 caregivers (77\%) aware of these HIV-positive results. Ten results (43\%) were found after review of laboratory databases (caregivers unaware in four cases). Three children were lost-to-care after previous ART and referred again.

\section{Discussion}

Mothers are the gateway to childhood HIV-prevention. We identified multiple missed opportunities along the PMTCT continuum, despite our data showing excellent access to routine maternal- and child healthcare ( $\geq 89 \%)$, except for postnatal care $(26 \%)$, which is in line with published reports (Chopra, Daviaud, Pattinson, Fonn, \& Lawn, 2009). Maternal HIV infection was mostly identified in the second or third trimesters (69\%), limiting timely ART interventions, while one-fifth of HIV diagnoses were only made post-delivery. We documented missed opportunities in post-test counselling $(13 \%)$ and psychosocial support $(83 \%)$, with frequent maternal HIV non-disclosure (61\%). Lack of support for pregnant newly-diagnosed HIVinfected mothers is of concern, since these initial steps were followed by multiple gaps along the ensuing care pathway, with maternal diagnosis not translating into universal care retention for mother-infant pairs, also described in other reports (Gourlay, Birdthistle, Mburu, Iorpenda, \& Wringe, 2013; Watson-Jones, Balira, Ross, Weiss, \& Mabey, 2012).

If PMTCT fails, early disease identification and ART initiation are essential to reduce mortality in infants with rapid disease progression, known since publication of the CHER-study in 2008 (Violari et al., 2008). This remains challenging though, with only few of our study participants $(\mathrm{n}=16 ; 6 \%)$ diagnosed before age three months and only four asymptomatic. Published South African data show greatly increased six-week PCR numbers in recent past, indicating a health system focus area (Barron et al., 2013), but only 31\% of study participants had a six-weeks HIVtest done, although our cohort also included older children who may not have benefitted from the more recent infant diagnosis scale-up. According to national PMTCT guidelines, HIVtesting should additionally occur after weaning and at 18 months (DOH, 2008), but a 
countrywide situational analysis (2010) showed that only $40 \%$ of sampled facilities offered all tests (Woldesenbet, Goga \& Jackson, 2012).

Paediatric HIV-testing needs are unlikely to be met if healthcare services continue to predominantly target HIV-exposed infants from the PMTCT programme who, because of maternal ART interventions, are at lower risk of HIV acquisition than those born to mothers with undocumented HIV infection (Rollins, Mzolo, Moodley, Esterhuizen \& Van Rooyen, 2009; Woldesenbet et al., 2012). Majority of study participants (82\%) presented with advanced/severe disease, particularly those aged 6-12 months (95\%), indicating health system failure in early identification of HIV-infected infants. Malnutrition was prominent, and microcephaly, associated with impaired brain growth, occurred in one-fifth of children, with early ART necessary for survival and good neurological outcomes (Crowell, Malee, Yogev, \& Muller, 2014). Childhood tuberculosis was additionally very common (35\%), reflecting the devastating effect of the adult HIV/TB co-epidemics on children (Hesseling et al, 2009). TB screening during pregnancy, potentially leading to reduced infant TB-exposure through maternal disease identification, was not done in majority of mothers $(72 \%)$, which requires intervention (Gounder et al., 2011).

Multiple entry points for paediatric HIV-testing are needed, guided by a clear strategy on paediatric case finding outside of PMTCT testing (Ahmed et al., 2013). This includes providerinitiated HIV-testing in paediatric wards and TB programmes in high-prevalence areas, with its well-described efficiency to identify previously undiagnosed children, although mortality in these children remains high due to late diagnosis (Ahmed et al., 2013; Kankasa et al., 2009; Mutanga et al., 2012). In our study majority of children were referred with advanced disease from hospital inpatient services $(61 \%)$, with resultant high death rate $(9 \%$ within six months). PMTCT is a very successful HIV-prevention strategy, but children who nonetheless acquire HIV still have a high mortality risk if untreated (Davies et al., 2009).

Early HIV identification at primary healthcare level is vital to prevent disease progression and link children to care. The IMCI strategy for improved child survival was adopted by South Africa in 1997 and later adapted to include a validated HIV component (DOH, 2011; Horwood, Liebeschuetz, Blaauw, Cassol \& Qazi, 2003; Horwood et al., 2010; Qazi \& Muhe, 2006). Effective implementation depends on health workers' knowledge, skills and willingness to identify HIV-infected children during routine care. In our study $53 \%$ of symptomatic children with documented features suggestive of HIV infection were not appropriately investigated, consistent with previously described suboptimal implementation, with skills weaknesses contributing towards non-testing of at-risk/symptomatic children (Ahmed et al., 2013; Horwood et al., 2010). Adequate recordkeeping is vital, as childhood HIV care otherwise depends on maternal HIV disclosure to healthcare workers, previously identified as problematic, and places children at risk who are not in maternal care (Ginsburg, Hoblitzelle, Sripipatana \& Wilfert, 2007; Horwood et al., 2010). We found gaps in documentation on patient-held records, like HIVtesting and infant feeding choice, while almost one-third of mothers visited a postnatal clinic different to their antenatal clinic, emphasising the crucial role of tools like patient-held records in promoting continuity of care (Woldesenbet et al, 2012). 
Additional strategies are sibling testing and targeted testing of children of $\mathrm{HIV}$-infected adults (Ahmed et al., 2013). In our study sibling testing had not been done in $68 \%$ of families, similar to a Malawian report showing $>80 \%$ of children of adult ART patients not tested for HIV, clearly indicating need for a more family-centred approach (Cohen, Lungu \& van Oosterhout, 2010; Koo, Makin \& Forsyth, 2013). As many as one-third of HIV-infected children have slow disease progression and survive to adolescence without treatment (Ferrand et al., 2007; Ferrand et al., 2009). One-quarter of our cohort were schoolchildren, therefore necessitating alternative strategies, like family testing, to prevent disease progression.

Substantial patient losses can occur at every stage of the HIV care pathway, and a positive HIV test does not equate to receiving appropriate care, as previously reported from India (Gupta et al., 2013) and Africa, where a pooled estimate from five studies showed 45\% loss-to-care (range 30\%-68\%) after early infant diagnosis programmes (Sibanda, Weller, Hakim, \& Cowan, 2013). In our study one-third of children had a previous HIV diagnosis, with three-quarters of caregivers aware of prior results and half acknowledged failing to attend the free ART services despite referral. These realities underline the pivotal role that caregivers play in children's healthcare pathway. Additionally we documented substantial loss-to-care after ART access (25\% in 36 months), even in severely symptomatic children referred from hospital wards, despite the onsite dedicated paediatric ART team (including social worker). In very ill children time for extensive caregiver counselling before ART-initiation may have been too short and the concomitant disease affliction with resultant high pill burden possibly problematic. Lost-to-care children could also have died. The care pathway is a dynamic process of linkage, retention, loss and re-engagement, making it hard to assess and challenging to deal with for clinicians when encountering children in need of life-saving care (Govindasamya, Ford, \& Kranzer, 2012; Kranzer, Govindasamy, Ford, Johnston, \& Lawn, 2012).

Multiple care barriers need to be overcome in a culturally sensitive manner if healthcare interventions are to reach high uptake (Sibanda et al., 2013). Previously documented care obstacles include maternal disbelief of own HIV diagnosis, fear of involuntary HIV disclosure, anxiety regarding possible child HIV infection, unfriendly healthcare workers, poor parental education, poverty, inadequate family support and stigma (Donahue, Dube, Dow, Umar, \& Van Rie, 2012; Horwood et al., 2010; Wachira, Middlestadt, Vreeman, \& Braitstein, 2012). Integration of child health services, PMTCT and ART programmes is vital, and clear guidance to health workers is necessary in dealing with the confidentiality dilemma of maternal HIV infection in relation to documentation of relevant child information, including HIV exposure (Horwood et al., 2010; WHO, 2010). Active follow-up to reduce loss-to-care is beneficial, as shown in Tanzania, but defaulter tracing needs to be part of health systems planning, implementation and monitoring if to be successful at scale (Nuwagaba-Biribonwoha et al., 2010). The new wardbased outreach teams, which are part of the current South African primary healthcare reengineering process, are ideally positioned to improve the follow-up of children at household level. Additionally family support groups, which were not active during the time of our study, can further potentially facilitate retention in care, while community mobilization and stigma reduction are vital to strengthen treatment and support of HIV-infected children within their family context (Sibanda et al., 2013). 
Study limitations include that this hospital-based ART site may not represent the broader population of HIV-infected children, although at time of study minimal paediatric ART initiation occurred at local primary healthcare facilities. In the interview subgroup information was selfreported by primary caregivers, with possible recall bias. Verbal information was validated using medical records as far as possible and translators were used to mitigate language barriers. It was not possible to ascertain the mode or timing of participants' HIV acquisition, and the PMTCT pathway was applied to all. Older children were not included in the interviews, as the questionnaire was designed to track the maternal-child PMTCT path until childhood diagnosis, requiring additional research in this group.

In conclusion, our data demonstrates substantial bottlenecks in paediatric HIV diagnosis and access to ART care, resulting in significant childhood morbidity and mortality. A clear strategy on case finding is essential to ensure multiple HIV-testing entry points for children missed by PMTCT testing, especially at primary healthcare level. Diligent use of patient-held records will potentially assist with identification and testing of at-risk children and retention in care. Multiple missed HIV care opportunities need attention to ensure high uptake of services, of which maternal non-attendance of paediatric ART services is especially worrisome and requires further exploration and urgent social interventions.

\section{Acknowledgements}

We thank all the mothers/ caregivers and the children who participated in the study, as well as the staff from the Kalafong Paediatric HIV services. We would also like to thank LAW Hahne and Pierre Meyer for the design of the clinic and study databases respectively, and Gayle Sherman for verification of the laboratory data. The last two authors are acknowledged for their $\mathrm{PhD}$ supervision of the first author, and Barbara English of the research office in the University of Pretoria's Faculty of Health Sciences is thanked for her copy editing of the manuscript.

\section{References}

Ahmed, S., Kim, M.H., Sugandhi, N., Phelps, B.R., Sabelli, R., Diallo, M.O., ... Kellerman, S.E. (2013). Beyond early infant diagnosis: case finding strategies for identification of $\mathrm{HIV}$-infected infants and children. AIDS, 27(Suppl. 2):S235-S245. doi: 10.1097/QAD.0000000000000099

Barron, P., Doherty, T., Sherman, G., Jackson, D., Bhardwaj, S., Robinson, P., \& Goga, A.E. (2013) Eliminating mother-to-child HIV transmission in South Africa. Bulletin of the World Health Organization, 19:70-4. doi:10.2471/BLT.12.106807

Chopra, M., Daviaud, E., Pattinson, B., Fonn, S., \& Lawn, J.E. (2009). Saving the lives of South Africa's mothers, babies, and children: can the health system deliver? Lancet, 374(9692):835-46. doi:10.1016/S01406736(09)61123-5

Cohen, D., Lungu, M., \& van Oosterhout, J.J. (2010). HIV testing coverage of family members of adult antiretroviral therapy patients in Malawi. AIDS Care, 22:1346-9. doi: 10.1080/09540121003720986

Crowell, C.S., Malee, K.M., Yogev, R., \& Muller, W.J. (2014). Neurologic disease in HIV-infected children and the impact of combination antiretroviral therapy. Reviews in Medical Virology, doi:10.1002/rmv.

Davies, M.A., Keiser, O., Technau, K., Eley, B., Rabie, H., van Cutsem, G., .. Moultrie, H. (2009). Outcomes of the South African National Antiretroviral Treatment Programme for children: the IeDEA Southern Africa collaboration. South African Medical Journal, 99:730-7. 
Department of Health (DOH), South Africa. (2000). Prevention of Mother-to-Child HIV Transmission and Management of HIV Positive Pregnant Women.

Department of Health (DOH), South Africa. (2004). National Antiretroviral Treatment Guidelines. First Edition. Retrieved from http://southafrica.usembassy.gov/media/2004-doh-art-guidelines.pdf

Department of Health (DOH), South Africa. (2008). Policy and guidelines for implementation of PMTCT programme. Retrieved from http://southafrica.usembassy.gov/root/pdfs/2008-pmtct.pdf

Department of Health (DOH), South Africa. (2011). Integrated Management of Childhood Illness (IMCI). Retrieved from http://www.rudasa.org.za/index.php/resources/document-library/category/6paediatrics?download=29:integrated-management-of-childhood-illness-booklet

Department of Health (DOH), South Africa. (2013). The South African Antiretroviral treatment guidelines, PMTCT guidelines. $\quad$ Retrieved from http://www.sahivsoc.org/newsroom/HIV-NewsContent?content $=$ documents\&slugurl $=$ the-south-african-antiretroviral-treatment-gu

Donahue, M.C., Dube, Q., Dow, A., Umar, E., \& Van Rie, A. (2012). 'They have already thrown away their chicken': barriers affecting participation by HIV-infected women in care and treatment programs for their infants in Blantyre, Malawi. AIDS Care, 24:1233-9. doi: 10.1080/09540121.2012.656570

Ferrand, R.A., Luethy, R., Bwakura, F., Mujuru, H., Miller, R.F., \& Corbett, E.L. (2007). HIV infection presenting in older children and adolescents: a case series from Harare, Zimbabwe. Clinical Infectious Diseases, 44:874-8. doi: $10.1086 / 511873$

Ferrand, R.A., Corbett, E.L., Wood, R., Hargrove, J., Ndhlovu, C.E., Cowan F.M., .. William, B.G. (2009). AIDS among older children and adolescents in southern Africa: projecting the time course and magnitude of the epidemic. AIDS, 23:2039-46. doi: 10.1097/QAD.0b013e32833016ce

Ginsburg, A.S., Hoblitzelle, C.W., Sripipatana, T.L., \& Wilfert, C.M. (2007). Provision of care following prevention of mother-to-child HIV transmission services in resource-limited settings. AIDS, 21:2529-32.

Gounder, C.R., Wada, N.I., Kensler, C., Violari, A., McIntyre, J., Chaisson, R.E., \& Martinson, N.A. (2011). Active tuberculosis case-finding among pregnant women presenting to antenatal clinics in Soweto, South Africa. Journal of Acquired Immune Deficiency Syndrome, 57:e77-84. doi:10.1097/QAI.0b013e31821ac9c1

Gourlay, A., Birdthistle, I., Mburu, G., Iorpenda, K., \& Wringe, A. (2013). Barriers and facilitating factors to the uptake of antiretroviral drugs for prevention of mother-to-child transmission of HIV in sub-Saharan Africa: a systematic review. Journal of the International AIDS Society, 16:18588. doi:10.7448/IAS.16.1.18588

Govindasamya, D., Ford, N., \& Kranzer, K. (2012). Risk factors, barriers and facilitators for linkage to antiretroviral therapy care: a systematic review. AIDS, 26:2059-67. doi:10.1097/QAD.0b013e3283578b9b

Gupta, A., Singh, G., Kaushik, P., Joshi, B., Kalra, K. \& Chakraborty, S. (2013). Early Diagnosis of HIV in Children below 18 months using DNA PCR Test - Assessment of the Effectiveness of PMTCT Interventions and Challenges in Early Initiation of ART in a Resource-Limited Setting. Journal of Tropical Pediatrics, 59:120-6. doi: $10.1093 /$ tropej/fms063

Hesseling, A.C., Cotton, M.F., Jennings, T., Whitelaw, A., Johnson, L.F., Eley, B., .. Schaaf, H.S. (2009). High incidence of tuberculosis among HIV-infected infants: evidence from a South African population-based study highlights the need for improved tuberculosis control strategies. Clinical Infectious Diseases, 48:108-14. doi: $10.1086 / 595012$

Horwood, C., Liebeschuetz, S., Blaauw, D., Cassol, S., \& Qazi, S. (2003). Diagnosis of paediatric HIV infection in a primary health care setting with a clinical algorithm. Bulletin of the World Health Organization, 81:858-66.

Horwood, C., Voce, A., Vermaak, K., Rollins, N., \& Qazi, S. (2010). Routine checks for HIV in children attending primary health care facilities in South Africa: Attitudes of nurses and child caregivers. Social Science \& Medicine, 70:313-320. doi:10.1016/j.socscimed.2009.10.002

Johnson, L.F. Access to antiretroviral treatment in South Africa, 2004 - 2011. (2012). Southern African Journal of HIV Medicine, 13:22-27.

Kankasa, C., Carter, R.J., Briggs, N., Bulterys, M., Chama, E., Cooper, E.R., ... Abrams, E.J. (2009). Routine offering of HIV testing to hospitalized pediatric patients at university teaching hospital, Lusaka, Zambia: acceptability and feasibility. Journal of Acquired Immune Deficiency Syndrome, 51:202-208. doi: 10.1097/QAI.0b013e31819c173f

Kellerman, S., \& Essajee, S. (2010). HIV Testing for Children in Resource-Limited Settings: What Are We Waiting For? PLoS Medicine, 7:e1000285. doi: 10.1371/journal.pmed.1000285 
Koo, K., Makin, J.D., \& Forsyth, B.W. (2013). Barriers to male-partner participation in programs to prevent motherto-child HIV transmission in South Africa. AIDS Education and Prevention, 25:14-24. doi: 10.1521/aeap.2013.25.1.14

Kranzer, K., Govindasamy, D., Ford, N., Johnston, V., \& Lawn, S.D. (2012). Quantifying and addressing losses along the continuum of care for people living with HIV infection in sub-Saharan Africa: a systematic review. Journal of the International AIDS Society, 15:17383. doi:10.7448/IAS.15.2.17383

Massyn, N., Day, C., Dombo, M., Barron, P., English, R., \& Padarath, A. (2013). District Health Barometer 2012/13. Durban: Health Systems Trust. Retrieved from www.hst.org.za

Mutanga, J.N., Raymond, J., Towle, M.S., Mutemb, S., Fubisha, R.C., Lule, F., \& Muhe, L. (2012). Institutionalizing provider-initiated HIV testing and counselling for children: an observational case study from Zambia. PloS One, 7:e29656. doi: 0.1371/journal.pone.0029656

Nuwagaba-Biribonwoha, H., Werq-Semo, B., Abdallah, A., Cunningham, A., Gamaliel, J.G., Mtunga, S., ... Abrams, E.J. (2010). Introducing a multisite program for early diagnosis of HIV infection among HIV-exposed infants in Tanzania. BMC Pediatrics, 10:44. doi: 10.1186/1471-2431-10-44

Qazi, S.A., \& Muhe, L.M. (2006). Integrating HIV management for children into the Integrated Management of Childhood Illness guidelines. Transactions of the Royal Society of Tropical Medicine and Hygiene, 100:10-3. doi: 10.1016/j.trstmh.2005.05.013

Rollins, N., Mzolo, S., Moodley, T., Esterhuizen, T., \& Van Rooyen, H. (2009). Universal HIV testing of infants at immunization clinics: an acceptable and feasible approach for early infant diagnosis in high HIV prevalence settings. AIDS, 23:1851-1857. doi: 10.1097/QAD.0b013e32832d84fd

Sibanda, E.L., Weller, I.V.D., Hakim, J.G., \& Cowan, F.M. (2013). The magnitude of loss to follow-up of HIVexposed infants along the prevention of mother-to-child HIV transmission continuum of care: a systematic review and meta-analysis. AIDS, 27:2787-97. doi: 10.1097/QAD.0000000000000027

Stephen, C.R., Bamford, L.J., Patrick, M.E, \& Wittenberg, D.F. eds. (2011). Saving children 2009. Five years of data. A sixth survey of child healthcare in South Africa. Pretoria: Tshepesa Press, MRC, CDC. Retrieved from www.childpip.org.za/documents/saving_children_2009.pdf

Violari, A., Cotton, M.F., Gibb, D.M., Babiker, A.G., Steyn, J., Madhi, S.A., ... McIntyre, J.A. for the CHER Study Team. (2008). Early antiretroviral therapy and mortality among HIV-infected infants. New England Journal of Medicine, 359: 2233-44. doi:10.1056/NEJM oa0800971

Wachira, J., Middlestadt, S.E., Vreeman, R., \& Braitstein, P. (2012). Factors underlying taking a child to HIV care: implications for reducing loss to follow-up among HIV-infected and -exposed children. Journal of Social Aspects of HIV/ AIDS, 9:20-29. doi: 10.1080/17290376.2012.665255

Watson-Jones, D., Balira, R., Ross, D.A., Weiss, H.A., \& Mabey D. (2012). Missed Opportunities: Poor Linkage into Ongoing Care for HIV-Positive Pregnant Women in Mwanza, Tanzania. PloS One, 7: e40091. doi: 10.1371/journal.pone.0040091

Woldesenbet, S., Goga, A.E., \& Jackson, D.J. for the SA EID study group. (2012). The South African Programme to Prevent Mother-to-Child Transmission of HIV (PMTCT): Evaluation of Systems for Early Infant Diagnosis in Primary Health Care Facilities in South Africa: Report on Results of a Situational Assessment, 2010. South African Medical Research Council. Retrieved from www.nhls.ac.za/assets/files/Situational $\% 20 \% 20$ assessment $\% 20$ report $\% 20$ final_10th\%20Oct12.pdf

World Health Organization (WHO). (2006). WHO Multicentre Growth Reference Study Group: WHO Child Growth Standards: Length/height-for-age, weight-for-age, weight-for-length, weight-for-height and body mass index-for-age: Methods and development. Retrieved from http://www.who.int/childgrowth/standards/technical_report/en/ index.html

World Health Organization (WHO). (2007). WHO Case Definitions of HIV for Surveillance and Revised Clinical Staging and Immunological Classification of HIV-related Disease in Adults and Children. Retrieved from http://www.who.int/childgrowth/en/

World Health Organization (WHO). (2010). PMTCT strategic vision 2010-2015: preventing mother-to-child transmission of HIV to reach the UNGASS and Millennium Development Goals. Retrieved from whqlibdoc.who.int/publications/2010/9789241599030_eng.pdf 